Dicle University Journal of Engineering (DUJE)

web: http://dergipark.gov.tr/dumf

Araştırma Makalesi / Research Article

\title{
Traverten Atıklarının Çimentolu Dolgu Malzemesi Olarak Kullanımında Renk ve Parlaklık Değerlerinin Araştırılması
}

\section{Investigation of Color and Brightness of Travertine Wastes Using Cementitious Filling Material}

\author{
Ali Sarışık ${ }^{*}$, Songül Can², Keziban Ürün \\ ${ }^{1}$ Harran Üniversitesi, İnşaat Mühendisliği Bölümü, Şanlıurfa, sariisikali@gmail.com \\ ${ }^{2}$ Harran Üniversitesi, İnşaat Mühendisliği Bölümü,Şanlıurfa, songul_537@hotmail.com \\ ${ }^{3}$ Afyon Üniversitesi, İnşaat Mühendisliği Bölümü, Afyon, keziban.urun@gmail.com
}

\begin{tabular}{|c|c|}
\hline MAKALE BİLGILERİ & ÖZET \\
\hline Makale geçmişi: & \multirow{6}{*}{$\begin{array}{l}\text { Doğal yapı malzemeleri, dünya çapında önemli bir potansiyele sahiptir. Gözenekli yapısı ile istenmeyen } \\
\text { travertenlerin dolgu işlemi ile ekonomiye kazandırılması ülkemiz açısından bir kazançtır. Dolgu işleminden } \\
\text { sonra plak yüzeylerde; dolgulu yapılmış yüzey ile travertenin kendi yüzeyi arasında parlaklık ve renk } \\
\text { farklılıkları olabilmektedir. Ülke ve dünya pazarı açısından, bu farklılıklar en doğru yöntemle giderilerek, } \\
\text { minimum seviyeye getirilmesi gerekmektedir. Bu çalışmada, endüstriyel fabrikadan alınan } 4 \text { farklı reçete ile } \\
\text { laboratuvar çalışmaları sonucunda oluşturulan reçeteler renk ve parlaklık açısından karşılaştırılmıştır. Yeni } \\
\text { reçetelerde renk ve parlaklık açısından daha uyumlu ve daha ekonomik olduğu için traverten atıkları } \\
\text { kullanılmıştır. Sonuç olarak renk ve parlaklık açısından orijinal plaka yüzeylerine yakın yeni yüzeyler elde } \\
\text { edilmiștir. }\end{array}$} \\
\hline Geliş: 29 Ocak 2020 & \\
\hline Düzeltme: 13 Şubat 2020 & \\
\hline Kabul: 13 Şubat 2020 & \\
\hline Anahtar kelimeler: & \\
\hline $\begin{array}{l}\text { Çimento dolgu, Traverten atığı, } \\
\text { Renk, Parlaklık, Dolgu recetesi }\end{array}$ & \\
\hline
\end{tabular}

Doi: $10.24012 /$ dumf.681606

\begin{tabular}{|c|c|}
\hline ARTICLE INFO & ABSTRACT \\
\hline Article history: & \multirow{6}{*}{$\begin{array}{l}\text { Natural building materials have significant potential worldwide. It is a gain for our country that the travertine } \\
\text { with its porous structure is added to the economy filling process. After filling the plate surfaces; There may be } \\
\text { differences in brightness and color between the filled surface and the surface of the travertine itself. In terms of } \\
\text { the country and the world market, these differences must be eliminated with the most correct method and } \\
\text { brought to a minimum level. In this study, } 4 \text { different recipes obtained from the industrial factory and the recipes } \\
\text { produced as a result of laboratory studies were compared in terms of color and brightness. Travertine wastes are } \\
\text { used in new recipes because they are more compatible and more economical in terms of color and brightness. As } \\
\text { a result, new surfaces were obtained close to the original plate surfaces in terms of color and brightness. }\end{array}$} \\
\hline Received: 29 March 2020 & \\
\hline Revised: 13 February 2020 & \\
\hline Accepted: 13 February 2020 & \\
\hline Keywords: & \\
\hline Travertine, Cement Filling, & \\
\hline
\end{tabular}

Brightness, Color, Roughness

\footnotetext{
* Sorumlu yazar / Correspondence

Ali Sarışık

$\triangle$ sariisikali@gmail.com
} 


\section{Giriş}

İnşaat sektöründe traverten yapı malzemeleri isteğe bağlı olarak gözenekli doğal haliyle veya dolgulu tercih edilir. Endüstriyel uygulamalarda traverten dolgu, çimentolu ve epoksili dolgu olarak üretimi yapılmaktadır. Traverten yapı malzemelerinin homojen bir görüntü verebilmesi için kullanılan dolguların, travertenin kendi atıklarından yapılmış olması, renk uyumunu daha kolay sağlar. Bu nedenden dolayı travertenlerin doldurulmasinda traverten atıklarının kullanılmasının daha uyumlu renk vermesine ve çevreye zarar verici atıklarında, endüstride yeniden kullanılmasından dolayı ekonomik bir işletmecilik örneği oluşturmaktadır.

Travertenin, yapı malzemesi olarak kullanılması aşamasında yapısındaki boşluklar estetik olarak kusur sayılabileceği gibi bu gözeneklerin doldurulması için genelde tercihen çimento dolgu kullanılır (Şentürk ve Sarıısık, 2003).

Çimentolu dolguların dayanımında su içeriği belirleyici bir faktördür. Su içeriğinin azalması macun dolgunun dayanımını artırmaktadır. Çimento miktarı arttıkça çimento dolgunun dayanımı da artmaktadır (Yılmaz ve diğ. 2004).

Çimentolar çok değişik türde üretilmekle birlikte bazı özel çimentolar farklı endüstriyel çalışmalar için kullanılmaktadır. Kalsiyum alümina (CA) çimentosu da bu çeşitlerden biridir. $\mathrm{Bu}$ çimento üretilirken kullanılan yöntemler gelenekseldir. Üretilmesi esnasında kireç hammaddesi yerine ikame olarak mermer atıkları kullanılır. Alüminyum kaynağı olarak boksit cevher yerine alüminyum hidroksit ikame edilerek farklı bir üretim yöntemi kullanılmaktadır. Geliştirilen üretim sayesinde ocaktan alınan ham maddenin üretimi, nakliyesi, boyut küçültmek için eleme ve sınıflandırma süreçleri kullanılarak hammaddelerin önceki yapılan çalışmalar dikkate alınarak doğrudan CA çimentosu üretimine başlanabilmektedir. Özellikle, endüstriyel atıkların üretimi esnasında boyut küçültülmesinin doğrudan olması ve istenilen boyutlara kadar hazır hale gelmesi büyük oranda enerji tasarrufu sağlar (Kavas, 2003).
Çimento dolgu karışımlarında, cila kalitesini azaltmak, ufalanmayı azaltmak, iklim koşullarına uygun olabilmesi için belirli oranlarda kalsit, kaolen, çimento ve ayrıca uygun miktarlarda oksit boyalar kullanilır. Çimento dolguda kullanılan travertenin atığının parlatılabilmesi için (2-7 gün) hava koşullarına ve karışım özelliklerine göre 1 hafta kadar kür süresi önerilmektedir. Kür ortamlarının doğru iklimlendirilmesi ve bazı beton kimyasalları kullanılarak bu süre kısaltılmaya çalışılmaktadır (Cevheroğlu, 2005).

Doğal taşların yapılarında bulunan çatlaklar, gözenekler ve mikro gözenekler, üretimleri esnasında ve sonrasında ortaya çıkan problemler dolgu uygulamasinı gerektiren nedenler arasında gelmektedir (Emanuel, 2003).

Günümüzde endüstriyel uygulamalarda doğal taş plakalarını sağlamlaştırmak için epoksi reçineler kullanılmaktadır(Kotasek, 2004).

Epoksi reçineler, birbirleri ile etkileşerek olağanüstü dayanıklı, kimyasal dirençli ve yapıştırma kuvveti yüksek çapraz bağlı ürünler meydana getiren polimer oluşturucu sistemlerdir (Selwitz, 1992).

$\mathrm{Bu}$ çalışmada, farklı traverten atıkları kullanılarak, 4 adet endüstriyel ve laboratuvar çalışmaları sonucunda reçeteler oluşturulmuştur. Yeni reçeteler ile elde edilen traverten plakaları renk ve parlaklık açısından karşılaştırılmıştır.

\section{Materyal ve Metot}

\section{Çalışmada kullanılan travertenler}

Araştırmada kullanılan yapı malzemeleri (Travertenler) için isimlendirmeler yapılmıştır. Fantastik Silver Traverten reçetesi için " $F$ " ismi , Klasik Silver Traverten reçetesi için " $\mathrm{C}$ " ismi, Seabed Traverten reçetesi için " $\mathrm{S}$ " ismi ve Noçhe Traverten reçetesi için ise " $\mathrm{N}$ " ismi kısaltmaları kullanılmıştır. Çizelge 1'de yapı malzemeleri için dolgu karışımında kullanılacak malzemenin tane boyutları verilmiştir. 
Çizelge 1. Travertenlerin Dolgu Reçetesi Tane Boyutlart

\begin{tabular}{lll}
\hline $\begin{array}{l}\text { Tane } \\
\text { Boyutu } \\
(\boldsymbol{\mu m}) \mathbf{1 0} \mathbf{1 0}^{\mathbf{2}}\end{array}$ & $\begin{array}{l}\text { Tane } \\
\text { boyut } \\
\text { Kodu }\end{array}$ & $\begin{array}{l}\text { Traverten } \\
\text { karısımlarının } \\
\text { isimlendirilmesi }\end{array}$ \\
\hline $\mathbf{- 1 0 + 8 , 5}$ & $\mathrm{P}$ & FP, SP, NP \\
$\mathbf{- 8 , 5 + 5}$ & $\mathrm{T}$ & FT, ST, NT \\
$\mathbf{- 5 + 3}$ & $\mathrm{Z}$ & FZ, SZ, NZ \\
$\mathbf{- 3 + 1 , 5}$ & $\mathrm{Y}$ & FY, SY, NY \\
$\mathbf{- 1 , 5 + 1 , 0 6}$ & $\mathrm{X}$ & FX, SX, NX \\
\hline
\end{tabular}

\section{Dolguda Kullanılan Malzemeler}

Beyaz çimentonun temel özellikleri arasında yüzey düzgünlüğü, görünüş güzelliği, dekoratif ve estetik özelliklere sahip olması, yüksek dayanım kazandırması, çok daha küçük boyutlarla üretilmesi, üretim teknolojisinin yüksek olması, üretimde kullanılan malzemelerin çok saf olması gibi özellikler siralanabilir. Traverten dolgunun ana maddesi olarak çimentolar kullanılacak olup, çalışmada kullanılması planlanan beyaz çimentonun kimyasal özellikleri Çizelge 2'de verilmiştir.

\section{Çizelge 2. Karışımlarda kullanılan çimentonun özellikleri. ( Beyaz çimento standart limitleri} (EN197-1)

\begin{tabular}{|c|c|c|c|}
\hline $\begin{array}{l}\text { Çimentodaki } \\
\text { elementler }\end{array}$ & $\begin{array}{l}\text { Çimsa } \\
\text { değerleri }\end{array}$ & Min. & Maks. \\
\hline $\mathrm{SiO}_{2}(\%)$ & 21,6 & $\ldots$ & \\
\hline $\mathrm{Al}_{2} \mathrm{O}_{3}(\%)$ & 4,05 & $\ldots$ & \\
\hline $\mathrm{CaO}(\%)$ & 65,7 & $\ldots$ & \\
\hline $\mathrm{SO}_{3}(\%)$ & 3,30 & & 4,0 \\
\hline $\operatorname{MgO}(\%)$ & 1,30 & $\ldots$ & \\
\hline $\mathrm{Fe}_{2} \mathrm{O}_{3}(\%)$ & 0,26 & $\ldots$ & \\
\hline $\begin{array}{l}\text { Çözünmeyen } \\
\text { Kalıntı (\%) }\end{array}$ & 0,18 & & 5,0 \\
\hline
\end{tabular}

Kalsit kullanilarak üretilen dolguda, beyaz çimento miktarının azalması maliyetin düşmesine olanak sağlamaktadır. Açık renkli kalsitler traverten dolguların üretilmesinde tercih edilmektedir. Dolgu karışımında kullanılan kalsitinin özelliklerine Çizelge 3'de yer verilmiş̧tir.
Çizelge 3. Karışımlarda kullanılan kalsitin kimyasal özellikleri

\begin{tabular}{ll}
\hline $\mathrm{SiO}_{2}(\%)$ & $\mathbf{0 , 2 8}$ \\
\hline $\mathrm{Al}_{2} \mathrm{O}_{3}(\%)$ & 0,11 \\
$\mathrm{Fe}_{2} \mathrm{O}_{3}(\%)$ & 0,009 \\
$\mathrm{CaO}(\%)$ & 54,9 \\
$\mathrm{MgO}(\%)$ & 1,1 \\
$\mathrm{P}_{2} \mathbf{O}_{5}(\%)$ & 0,01 \\
$\mathrm{~K}_{2} \mathrm{O}(\%)$ & 0,01 \\
$\mathrm{SO}_{3}(\%)$ & 0,02 \\
$\mathrm{KK}_{(\%)}(\%)$ & 42,5 \\
$\mathrm{CaCO}_{3}(\%)$ & 97,45 \\
\hline
\end{tabular}

Pigmentler çimento dolgu üretiminde renk verici olarak kullanılmaktadır. Pigment boyalar yüksek oranda oksit içerirken demir oksit yüzdesi en yüksek orandadır. Oksitlerin siyah, sarı, kırmızı ve kahve gibi renkleri mevcuttur. Oksitler pigment boyalarda kullanıldığında çok yüksek derecede renk uyumu sağlamakla birlikte isıya dayanıklı oksitlerde mevcuttur. En yüksek 1sıya dayanıklı $\left(1000^{\circ} \mathrm{C}\right)$ oksit ise kırmızı demir oksittir.

\section{Boyut Belirlenmesi}

Reçetelerde kullanılan traverten atıklarının boyutları, silim abrasivlerinin temas ettiği yüzeyin parlaklık ve renk uyumunda iyileşmeye katkı sunacağı şekilde sinıflandırılmalıdır. Traverten dolgu işlemi yapılırken en önemli parametre, dolgu karışımlarında kullanılan kalsit $\left(\mathrm{CaCO}_{3}\right)$ yerine traverten atığının ikame edilmesi işlemi olmuştur. Çalışma kapsamında, mermer tesislerinde kullanılan karışımlarda

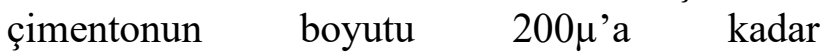
çıkabilmektedir. Karışımlarda kullanılan travertenin boyutu ne kadar küçültülürse yüzey alanı artacağından dolayı parlaklık ve renk kalitesinde iyileşme olabileceği düşünülmüştür. Bu karışımlarda traverten atıklarının daha küçük boyutlarda kullanılması, doğru sinıflandırılmasına tabi tutulmasinı zorunlu hale getirmiştir.

\section{Reçetelerin Belirlenmesi}

$\mathrm{Bu}$ çalışmada oluşturulan yeni karışımların isimlendirilmesinde $\mathrm{X}$-Y-Z-T-P boyut isimleri olarak traverten atıkları sınıflandırılmıştır. Kullanılan atıkların oranları \%70-\%50-\%30 oranlarında kullanılmış, oksit boya pigmentleri 
ise çimento oranı sabitlenerek tesis karışımlarına uygulanmaya çalışılmıştır.

\section{Reçete Boyutlart}

Traverten atıklarının tane iriliği belirlenirken etkili parametrelerden bazıları; kullanılacak atıkların homojenliği, pürüzlügü ve görünümü ile alakalı çalışmaları planlayacak şekilde yapılmıştır. Çalışmalarda kullanılacak karışımlarda, ikame olarak traverten atığı kullanılırken birbirine yakın görülen karışımlarda renk, parlaklık ve pürüzlülük ölçümleri yapılarak karşılaştırılmalı olarak kıyaslanmıştır.

\section{Noçe traverten reçetesi}

Çalışmalarda kullanılan karışımlarda çimento oranı $\% 30$ 'dan başlayarak $\% 50$ ve $\% 75$ 'e kadar azaltılmıştır. Traverten plakaları, su ile kesildiği için, plakalar yeterince bünyesinde su tutmaktadırlar. Travertenin gözenekli yapısından dolayı, gözeneklere giren su, traverten plakanın nem miktarını artırır. $\mathrm{Bu}$ nedenle karışımda ekstra su ihtiyacını gerek yoktur. Reçeteler hazırlandiktan sonra, dolgu makinesinin malzeme haznesine kuru toz olarak dökülmektedir. Islak haldeki traverten plakada bu haznenin, altında kalacak şekilde yerleştirilmiş olduğu için, haznedeki toz haldeki dolgu malzemesi, su ve nem ile buluştuğunda, çimentolu dolgu macunu haline gelmektedir. Dolgu macunu haline gelen karışım reçetesi, makine yardımı ile traverten plaka yüzeyine sürülerek gözenekler doldurulur. $\mathrm{Bu}$ işlemden sonra traverten plaka en az 1 gün veya iklim koşullarına göre 2 güne yakın süre zarfında doğal ortamda kürlemeye bırakılır. Kürlemesi tamamlanan traverten plaka yüzeyleri silinmesi ve parlatılması için yüzey işleme makinelerin olduğu üretim bandına yerleştirilerek, yüzey parlatma ve cilalama işlemleri başlatılmıştır. Sarı, açık kahve ve oksitli siyah renkler kullanılırken, travertenlere renk açısından daha uyumlu olan tercih edilmiş ve karışımlarda kaolen ile birlikte kullanılmıştır. Bu karışımlarla oluşturulmuş tesis reçetelerinden Noçe traverten tesis reçetesi karışımları Çizelge 4'de gösterilmiştir.

\section{Çizelge 4. Tesiste Kullanılan Noçe Traverten Reçetesi}

\begin{tabular}{lll}
\hline Reçeteler & Numune & Miktar (gr) \\
\hline & Gri çimento & $20.000,00$ \\
& Beyaz çimento & $50.000,00$ \\
Örnek işletme & Kaolen & $1.500,00$ \\
Reçetesi & Oksit sarısı & $1.500,00$ \\
& Oksit siyah & 100,00 \\
& Açık kahve & $1.300,00$ \\
\hline
\end{tabular}

Tesis reçetesi baz alınarak geliştirilen yeni reçeteler Çizelge 5'de verilmiştir. Travertenler önce kırma, eleme ve ögütme işlemlerinden geçirildikten sonra hazırlanan karışımlara çimento yerine $\% 30, \% 50$ ve $\% 75$ oranlarında ikame edilmiştir. 4 farklı reçetede farlı boyutlar (X-Y-Z-T-P) baz alınmış ve her boyut için travertenler $\% 30, \% 50$ ve $\% 70$ oranlarında çimento yerine ikame edilerek her bir traverten reçetesi için 15 seri karışım hazırlanmıştır. $\mathrm{Bu}$ çalışmada en yaygın kullanılan Noçe Traverten reçetesi ile ilgili analiz sonuçlarına yer verilmiştir.

\section{Çizelge 5. Tesiste Geliştirilen Noçe Traverten Reçetesi Karışım Miktarları}

\begin{tabular}{llll}
\hline Malzemeler & \multicolumn{3}{c}{ Traverten atık oranları } \\
\hline & $\% 30$ & $\% 50$ & $\% 75$ \\
\hline $\begin{array}{l}\text { Gri çimento } \\
\text { Beyaz }\end{array}$ & 190,47 & 190,47 & 190,47 \\
çimento & 476,18 & 476,18 & 476,18 \\
Kaolen & 14,28 & 14,28 & 14,28 \\
Oksit sarısı & 14,28 & 14,28 & 14,28 \\
$\begin{array}{l}\text { Oksit siyahı } \\
\text { Açık kahve }\end{array}$ & 0,95 & 0,95 & 0,95 \\
$\begin{array}{l}\text { Boyutlu } \\
\text { traverten }\end{array}$ & 32,38 & 12,38 & 12,38 \\
\hline
\end{tabular}

\section{Renk ve Parlaklık Ölçümü}

1936 yılından itibaren parlaklık ölçümü üzerine çalışmalar yapılmaktadır (ASTM D 523-94). Metal, kağıt, boya kaplamalı malzemeler üzerine değişik metotlar kullanılarak bir çok parlaklık ölçümler yapılmıştır (Hunter, 1975; Budde, 1980). Yapılan çalışmada üretilen plakaların yüzeylerinde yapılacak renk ve parlaklık ölçümleri yapılırken $20^{\circ}, 60^{\circ}$ ve $85^{\circ}$ 'lik projelendirme açıları ile gelen yansıma dikkate alınarak kullanılan ölçüm aracı ile 
analizler gerçekleştirilmiştir. Üretilen karışımların uygulandığı fayanslarda $60 \times 30 \mathrm{~cm}$ ebatları dikkate alınarak bu boyutlardaki plakalarda, cetvel ile ölçüm yapılarak karelere $(10 \times 10 \mathrm{~cm})$ ayrılıp ayrılan kareler içinde her biri üzerinde 5 adet okuma gerçekleştirilmiştir. Çalışmanın sonucunda elde edilen veriler ile plakaların parlaklık ve renk ölçümleri yapılarak her ölçüm öncesi makinanın kalibresi yenilenmiştir.

\section{Sonuçlar ve Tartışmalar XRF analizi}

Kimyasal analizler TÜRKAK tarafından akredite olan doğal taş analiz laboratuvarında (Afyon) X-Işını Flüoresans (XRF) yöntemi ile yapılmıştır. Kimyasal analiz sonuçları Çizelge 6'de verilmiştir.

\section{Çizelge 6. Kullanılan Karışım Reçetelerinin (XRF) Analiz Sonuçları}

\begin{tabular}{lllll}
\hline $\mathbf{K o d}(\%)$ & $\mathbf{N}(\%)$ & $\mathbf{S}(\%)$ & $\mathbf{C}(\%)$ & $\mathbf{F}(\%)$ \\
\hline $\mathbf{S i O}_{\mathbf{2}}$ & 0,25 & 0,50 & 0,05 & 0,06 \\
$\mathbf{A l}_{\mathbf{2}} \mathbf{O}_{\mathbf{3}}$ & 0,09 & 0,21 & 0,02 & 0,01 \\
$\mathbf{F e}_{\mathbf{2}} \mathbf{O}_{\mathbf{3}}$ & 0,03 & 0,31 & 0,01 & 0,01 \\
$\mathbf{C a O}$ & 55,28 & 54,9 & 56,13 & 56,32 \\
$\mathbf{M g O}$ & 0,23 & 0,20 & 0,06 & 0,04 \\
\hline
\end{tabular}

\section{SEM ve EDX analizleri}

Çalışmada kullanılan numunelerin kırık yüzey büyüklüğü $10 \mathrm{~mm}$ çapında numuneler üzerinde, malzemenin yapısı ve malzemenin karekterizasyonunu gösterecek şekilde yüzeyler tespit edilmiştir. AKÜ Teknoloji Uygulama ve Araștırma Merkezi'nde traverten örnekler $250^{\circ} \mathrm{C}-300^{\circ} \mathrm{C}$ ' de ince karbon filmle kaplanarak SEM analizleri görüntelenmiştir. Malzemelerin kırık yüzeylerine EDX (enerji dağılımlı spektrometre) ve SEM (Taramalı elktron mikroskobu) analizleri yapılmıştır. Yap1 malzemesi olan, Noçe Traverten'in iç yapısını göstermek için çekilen Taramalı elektron mikroskobu (SEM) fotoğrafi Şekil 1-2'de gösterilmektedir. Şekil üzerinde görülen iç yapının daha iyi analiz edilebilmesi için işaretin olduğu noktada kimyasal elementleri bulmak üzere (EDX) analizler gerçekleştirilmiştir. Şekil 1 'de belirlenen noktada yapilan analiz sonucu iki temel elementin varlığı dikkat çekmektedir.
İşaretli noktada yapılan analizde, $\mathrm{Ca}$ (kalsiyum) ve $\mathrm{O}$ (oksijen) elementinin olduğu tespit edilmiştir. Yapılan bu analiz incelendiğinde; en büyük pikin kalsiyumda, ondan sonraki ikinci pikin ise oksijen elementinde olduğu gözlemlenmiştir. Yapılan görüntü üzerindeki analizlerde işaretli noktalarda daha çok kalsit minarelleri bulunmuştur. Şekil 2'de EDX analiz sonucu gösterilmektedir.

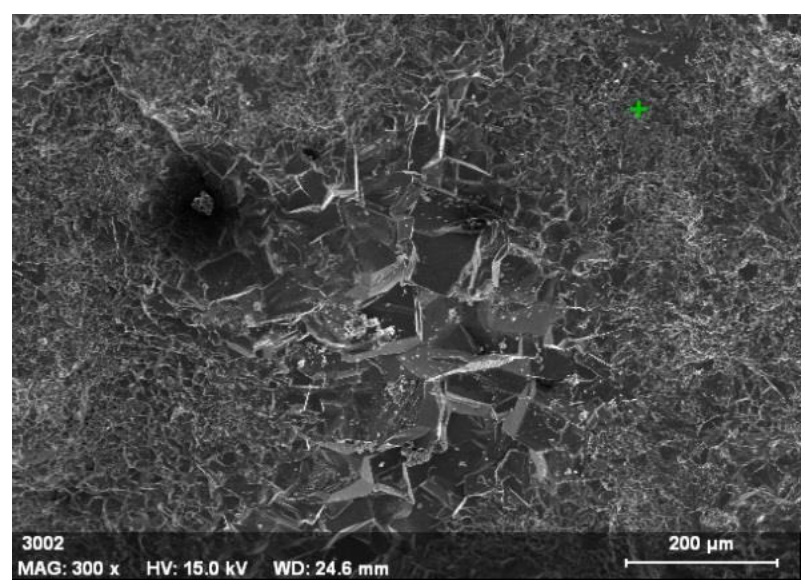

Şekil 1. Traverten SEM görüntüsü (N 300x görünümü)

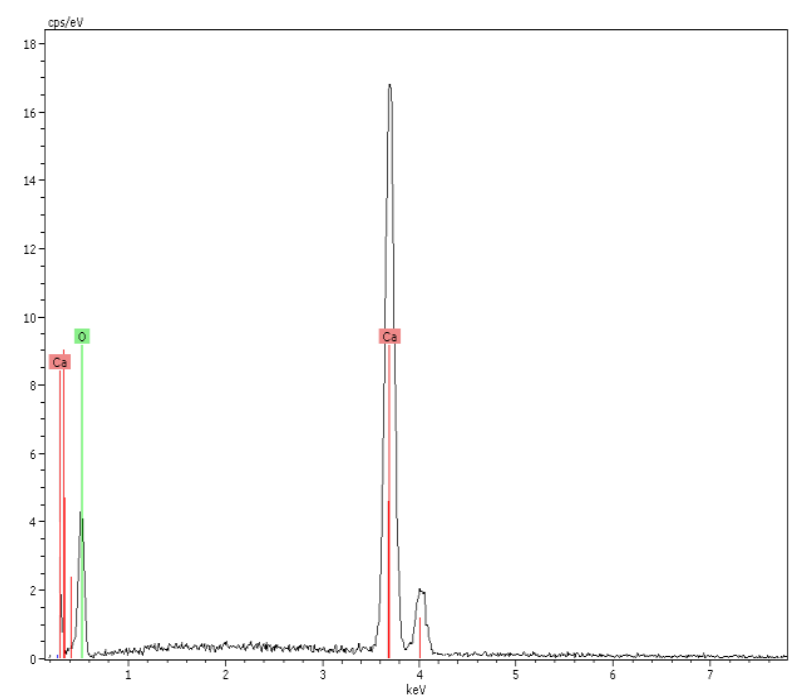

Şekil 2. EDX nokta görüntü analiz sonucu (N 300x görüntüsünde işaretli nokta)

\section{Noçhe traverten reçetelerin karşılaştırılması}

Tesiste kullanılan reçete ile laboratuvarda geliştirilen reçeteler renk ve parlaklık açısından karşılaştırılmıştır. Şekil 3'de Noçe traverten için gözenek yapısı, Şekil 4'de ise kür aşamasındaki gözenek görüntüsü gösterilmektedir. İnşaat sektöründe en yaygın kullanılan Noçe traverten 
olduğu için Noçe travertenle ilgili analiz sonuçlarına yer verilmiştir.

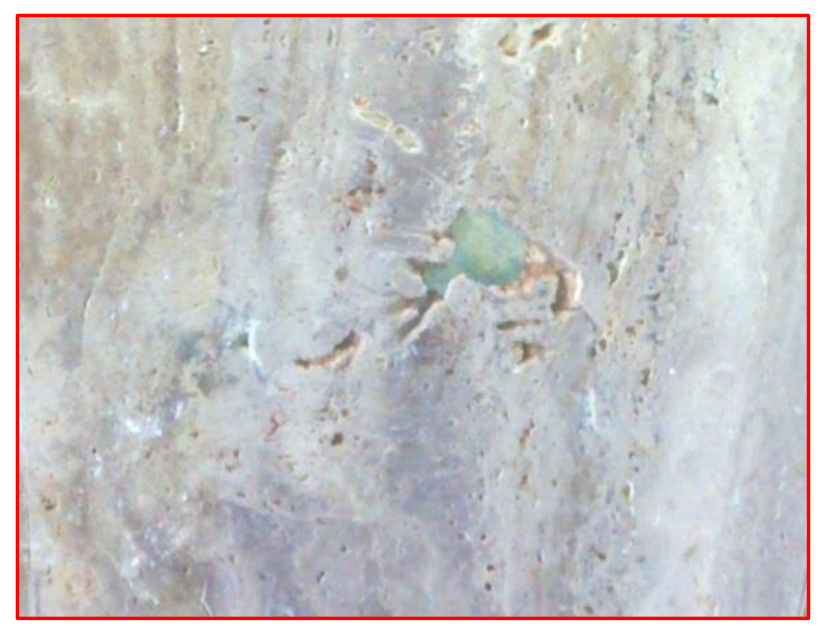

Şekil 3. Noçe traverten gözenek yapısı

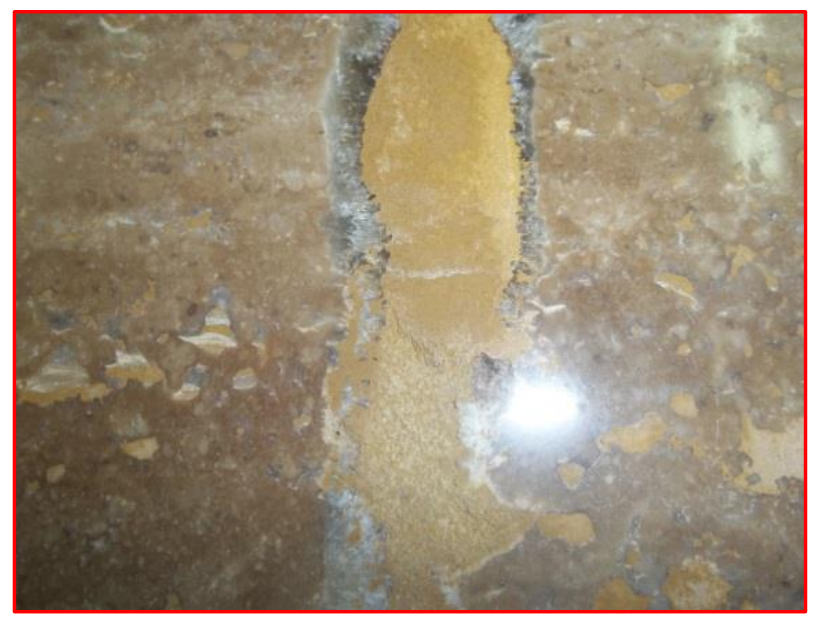

Şekil 4. . Noçe traverten kür aşamasındaki gözenek görüntüsü

Hazırlanan 4 farklı reçete için renk ve parlaklık ölçümleri yapılmıştır. Çizelge 7'de reçetelerin parlaklık değerlerinin ortalamaları verilmiştir. Hazırlanan 4 farklı reçetede faklı açılar oluşturularak parlaklık sonuçları bulunmuştur. Şekil 5'de malzemenin (N) parlaklık değerlerinin ölçüm sonuçları verilmiştir.

Parlaklık analizinde kullanılan 1.5+1.06x $10^{2}$ $\mu \mathrm{m}$ boyutlu \%30 traverten atığ ikamesi (A1), $1.5+1.06 \times 10^{2} \mu \mathrm{m}$ boyutlu $\% 50$ traverten atı ${ }_{1}$ ikame ikamesi (A2), $-1.5+1.06 \times 10^{2} \mu \mathrm{m}$ boyutlu $\% 30$ traverten atığı ikamesi (A3), $3+1.5 \times 10^{2} \mu \mathrm{m}$ boyutlu \%30 traverten atığ1 ikamesi (B1), $3+1.5 \times 10^{2} \mu \mathrm{m}$ boyutlu $\% 75$ traverten at1 1 ikamesi (B2), $\quad-3+1.5 \times 10^{2} \mu \mathrm{m} \quad \% 75$ boyutlu traverten atığ 1 ikamesi, $3+1.5 \times 10^{2} \mu \mathrm{m}$ boyutlu \%75 traverten atığ1 ikamesi (B3) ve Noçe traverten ( NT, atıksız) ölçüm sonuçları, Şekil 5'de ve Şekil 6'da verilmiştir. Bu sonuçlarda; en yüksek parlaklık değerleri $20^{\circ}$ 'lik açıda oluşurken en düşük parlaklık değerlerinin $60^{\circ}$ 'lik açılarda olduğu görülmüştür.

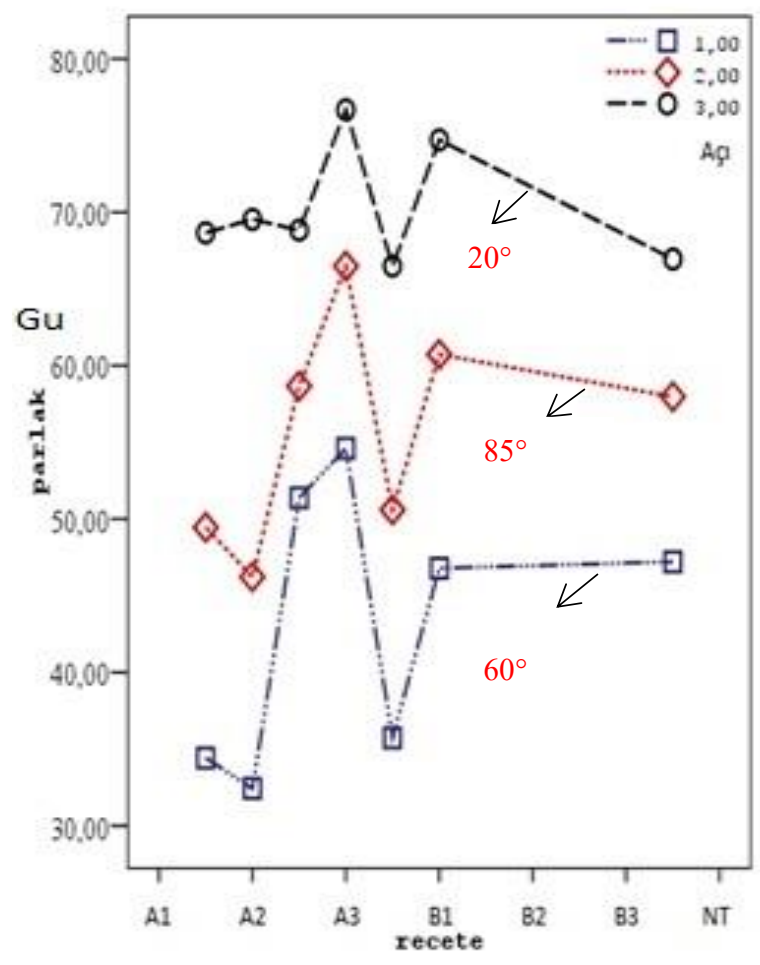

Şekil 5. Malzemenin parlaklık değerlerinin ölçüm verileri $(N)$

4 farklı reçete için farklı boyutlarda kullanılan traverten atığının Noçe traverten reçetesi için renk değerlerinin aritmetik ortalaması Çizelge 8 'de gösterilmektedir. 


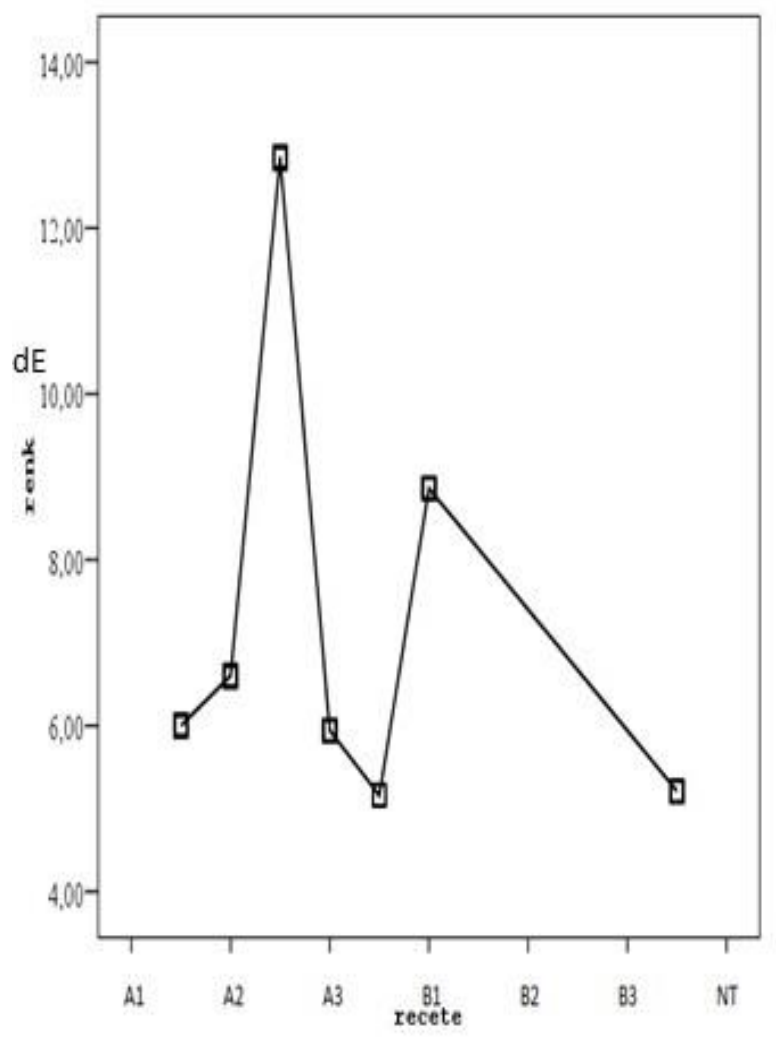

Şekil 6. Parlaklık dĕgerlerinin analizi (N)

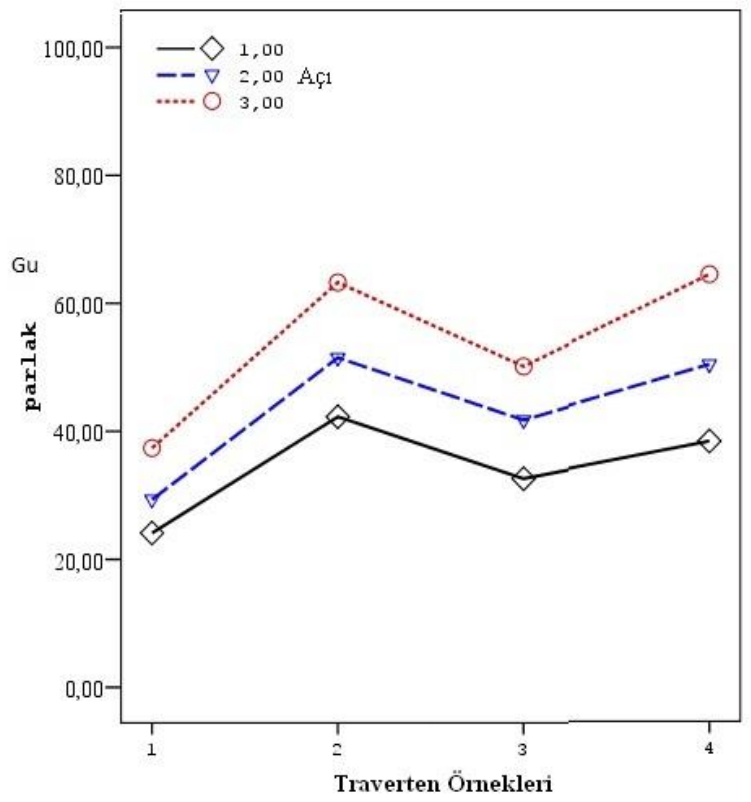

Şekil 7. Malzemelerin parlaklık değgerleri ( T4, $T 3, T 2, T 1)$

Traverten ölçümlerinde genel olarak parlaklık değerlerinin en yüksek olduğu nokta $85^{\circ}$ lik açıda oluşurken, $20^{\circ}$ 'lik açı ile yapılan okumalarda en düşük değere ve $60^{\circ}$ 'lik açı ile yapılan okumalarda ise orta değerlere ulaşılmıştır (Şekil.7).

Çizelge 7. Traverten 3: Hazırlanan karışımlar ile oluşturulmuş parlaklık sonuçları

\begin{tabular}{|c|c|c|c|c|c|c|c|c|c|c|c|c|c|}
\hline Noçe(T) & $\% 75$ & $\% 50$ & $\% 30$ & $\% 75$ & $\% 50$ & $\% 30$ & $\% 75$ & $\% 50$ & $\% 30$ & $\% 75$ & $\% 50$ & $\% 30$ & TESIS \\
\hline $\mathrm{T}\left(10^{-6} \mathrm{~mm}\right)$ & \multicolumn{3}{|c|}{$-150+106$} & \multicolumn{3}{|c|}{$-300+150$} & \multicolumn{2}{|c|}{$-500+300$} & \multicolumn{5}{|c|}{$-850+500$} \\
\hline Gu & NX3 & NX2 & NX1 & NY3 & NY2 & NY1 & NZ1 & NZ2 & NZ3 & NT1 & NT2 & NT3 & NT \\
\hline $20^{\circ}$ & 51.37 & 32.42 & 34.42 & 46.79 & 35.73 & 54.6 & - & - & - & - & -- & - & 47.21 \\
\hline $60^{\circ}$ & 58.67 & 46.22 & 49.45 & 60.73 & 50.6 & 66.49 & - & - & - & - & - & - & 57.97 \\
\hline $85^{\circ}$ & 68.83 & 69.54 & 68.66 & 74.72 & 66.49 & 76.68 & - & - & - & - & - & - & 66.94 \\
\hline
\end{tabular}

Çizelge 8. Traverten 3: Hazırlanan karşımlar ile oluşturulmuş renk değerlerinin sonuçları

\begin{tabular}{|c|c|c|c|c|c|c|c|c|c|c|c|c|}
\hline $\begin{array}{l}\text { Karışım } \\
\text { reçeteleri }\end{array}$ & $\begin{array}{l}(\%) \\
\text { trav. }\end{array}$ & $\begin{array}{l}\begin{array}{l}\text { Boyut } \\
(\mu \mathrm{m})\end{array} \\
\end{array}$ & $\mathbf{L}$ & $\overline{\mathbf{a}}$ & b & $\mathbf{L}$ & $\bar{C}$ & $\mathbf{H}^{\mathbf{0}}$ & $\mathrm{dE}$ & dL & da & $\mathbf{d b}$ \\
\hline NX1 & 30 & $\begin{array}{l}-150+ \\
106\end{array}$ & 54.57 & 9.91 & 17.59 & 54.57 & 20.29 & 60.37 & 6 & 0.37 & -0.29 & -13.84 \\
\hline NX2 & 50 & $\begin{array}{l}-150+ \\
106\end{array}$ & 56.71 & 10.23 & 16.97 & 56.71 & 19.95 & 58.33 & 6.6 & 1.79 & -0.21 & -7.7 \\
\hline NX3 & 75 & $\begin{array}{l}-150+ \\
106\end{array}$ & 53.68 & 10.44 & 20.24 & 53.68 & 22.9 & 62.58 & 12.85 & -12.2 & 0.29 & 24.25 \\
\hline NY1 & 30 & $\begin{array}{l}-300+ \\
150\end{array}$ & 53.86 & 11.19 & 20.23 & 53.86 & 23.22 & 60.7 & 5.94 & 4.69 & -1.83 & -0.65 \\
\hline NY2 & 50 & $\begin{array}{l}-300+ \\
150\end{array}$ & 54.82 & 10.83 & 19.86 & 54.82 & 22.7 & 61.29 & 5.16 & 1.26 & 0.22 & -19.85 \\
\hline NY3 & 75 & $-300+$ & 53.65 & 10.77 & 19.72 & 53.65 & 22.57 & 61.75 & 8.86 & -6.38 & 2.65 & -5.66 \\
\hline
\end{tabular}




\begin{tabular}{lllllllllllll}
\hline & & 150 & & & & & & & & & & \\
NT & - & - & 55.28 & 10.95 & 18.76 & 55.28 & 21.81 & 59.37 & 5.21 & -3.75 & 1.19 & 0.4 \\
\hline
\end{tabular}

Traverten atıklarından elde edilen dolgu malzemesin boyutları $-500+300 \times 10^{-6} \mathrm{~mm}$ ve $850+500 \times 10^{-6} \mathrm{~mm}$ aralıklarında değişen numunelerin, boyutları iri olduğundan karışım elde edilerek, yapılan dolgularda, dökülmeler olmuş, bundan dolayı; reçetelerin parlaklık ve renk değerleri ölçülememiştir.

\section{Sonuçlar}

İnşaatlarda yapılan malzemelerde kullanılan travertenler, çimento dolgulu olarak istenildiği takdirde kullanılan renkler travertenin orijinal renginden koyu veya açık olabilmektedirler. Tesislerde yapılan reçetelerde; gözenekli travertenlere, çimentolu dolgular yapıldığında oluşturulan renk, travertenin orijinal rengi dışında mat bir görüntü verebilmektedir. $\mathrm{Bu}$ çalışma ile birlikte inşaat yapı malzemesi olarak kullanılan gözenekli travertenlerin, orjinal kendi atıkları ile doldurulan, çimentolu dolgu karışımları kullanılarak çok daha verimli sonuçlar elde edileceği kanısına varılmıştır.

Traverten atıkları kullanılarak üretilen dolgulu reçetelerde atıklar, çimento miktarının belirli yüzdeleri alınarak kullanılmış ve 4 tesis reçetelerine uygulanarak farklı reçeteler hazırlanmıştır. Dolgu yapılan traverten reçeteleri, tesiste kullanılan reçete ile kıyaslandığında parlaklık ve renk açısından iyileşmeler olduğu gözlemlenmiştir.

Afyon Kocatepe Üniversitesi Mühendislik Fakültesinde yapılan karışımlar ile hazırlanan çimentolu dolguların kullanılması ile elde edilen numunelerin karekterizasyonunun incelenmesi sonucunda bulunan veriler kıyaslamalı olarak incelenmiştir. Çalışma kapsamında üretilen dolgulu reçetelerin karekterizasyon özellikleri incelendiğinde; Fantastik Silver karışımlarından elde edilen Traverten 1 örnekleri için en uygun reçete; parlaklık değerinin \% 80' lere ulaştığ Y2 reçetesidir. Renk değerleri açısından kıyaslandığında ise bulunan reçete örnek işletme reçetesine göre parlaklık açısından \%50 iyileşme sağlamıştır.

Çalışma kapsamında elde edilen sonuçlar tesiste kullanılan reçetelere göre daha parlak traverten fayansları üretilmesine imkan sağlamıştır.
Sonuç olarak, Noçe Traverten için uygun olan Y2 reçetesi $-3+1.5 \times 10^{2} \mu$ tane boyutuna sahip atık traverten tozları kullanılabilir. Bu çalışma ile üretilen reçeteler normal sanayideki tesiste kullanılan reçetelere göre $\% 50$ oranında daha az çimento kullanılmasını sağlamıştır. Klasik Silver için en uygun olan karışım \%80'lere yakın parlaklık değeri veren $\mathrm{Y} 2$ reçetesidir. Uygulamas1 yapılan traverten plakalarında renk değerleri tesisteki karışım sonucu elde edilen renklere göre daha orijinale yakın doğal renkler ortaya çıkmasını sağlamış, parlaklık değerleri \% 45'lere ulaşmıştır. Sonuç olarak Y2 reçetesinde $-3+1.5 \times 10^{2} \mu$ tane boyutuna sahip malzemeler kullanılabilir.

Noçe için hazırlanan Traverten 3 örnek karışımlarında Y1 reçetesinde \% 80'lere yakın daha parlak sonuçlar elde edilmiştir ve sanayide kullanılan reçeteye göre bu oran $\% 30$ daha parlak ürünler elde edilmesine imkan sağlamıştır. Sonuç olarak Noçe Traverten için $300+150 \mu$ tane boyutuna sahip traverten atıklar1 kullanılması önerilmektedir. Bu karışımlar ile oluşturulmuş reçetelerde, çimento oranında $\% 30$ azalma sağlanmıştır.

Seabed için oluşturulan Traverten 4 karışımlarında Y3 reçetesinin parlaklık değerleri \%80'lere çıkmıştır. Renk değerlerinde biraz sapma olmasına rağmen sonuç olarak, Y3 reçetesi olan $-300+150 \mu$ tane boyutuna sahip traverten atı malzemelerinin kullanılmasi önerilmektedir. Yapılan analizler sonucunda bu reçeteler sanayide üretilenlere göre çimentodan \%75 oranında azalma sağlamıştır. Yapılan sanayi boyutlu ve laboratuvar boyutlu çalışma ile beraber traverten yap1 malzemelerinin kalitesi artmış ve atık traverten boyutları küçültülerek elde edilen karışımlarda çimento oranı düşürülmüş, renk açısından doğal renge 
daha yakın renkler üretilmiş ve ekonomiye ciddi katkılar sağlanmıştır.

\section{Kaynaklar}

[1] A.Şentürk, ve A. Sarışık, 'Doğal Taş Tamirinde Epoksi, Polyester, Mastik ve Çimento Dolguların Uygulanma Kriterleri', MERSEM 2003 Sempozyumu, 11-13 Eylül, 553-565, (2003).

[2] E. Yılmaz, A. Kesimal, ve B, Erçıkdı, 'Malzeme Bileşiminin Çimentolu Macun Dolgu Dayanımı Üzerine Etkisi”, Kayamek2004 7. Bölgesel kaya mekaniği sempozyumu, 21-22 Ekim, 1-5, Sivas, (2004).

[3] Taner Kavas, "Atık mermer ve alüminyum hidroksit kullanarak refrakter çimento üretimi', Doktora Tezi, Osmangazi Üniversitesi Fen Bilimleri Enstitüsü, Eskişehir, 2003.

[4] Sümeyra Cevheroğlu, 'Diyarbakır Yöresindeki Bazı Mermer Türlerine Uygulanan Dolgu Yöntemlerinin Performanslarının Değerlendirilmesi', Yüksek Lisans Tezi, Çukurova Üniversitesi Fen Bilimleri Enstitüsü, Adana, 2005.

[5] H. Ceyla, S. Saraç, ve H.T. Özkahraman, " Mermer Toz Atıklarının Derz Dolgu Malzemesi (Fuga) Üretiminde Kullanılabilirliğinin Araştırılması', III. Mermer Sempozyumu, 3-5 Mayıs, Afyon, ( 2001).

[6] A. Çiftlik, "Kaolen cevherinden metallerin liç yöntemi ile uzaklaştırılması" , Yüksek Lisans Tezi, Süleyman Demirel Üniversitesi Fen Bilimleri Enstitüsü, Isparta, 2010.

[7] S. Dönmez, ve Y.D. Sarı, 'Sayısal Görüntü Analizi Tabanlı Bir yüzey Parlaklık Ölçüm Sistemi', Mühendislik Bilimler Dergisi 11(3) , 401- 405, 2004.

[8] S. Kulaksız, S, 'Doğaltaş (Mermer) Maden İşletmeciliği ve İşleme Teknolojileri', Ankara, 7159, (2007).

[9] A. Şentürk, A. Sarışık, A, 'Doğal Taş Tamirinde Epoksi, Polyester, Mastik ve Çimento Dolguların Uygulanma Kriterleri'”, MERSEM 2003 Sempozyumu, 11-13 Eylül, 553-565, (2003).

[10] F. Emanuel,, The Marble and Granit Resin Process: How and Why, 2003.

[11] C. Selwitz, Epoxy Resins in Stone Conservation, 1992.

[12] W. Budde, 'Stability problems in gloss measurements", Journal of Coatings Technology, (52), 4-48, 1980.

[13] ASTM D 523, Standard Test Method for Secular Gloss, 6.01, 32-36, (1994).

[14] R.S.Hunter, The Measurement of Appearance, Wiley Interscience, New York, 1975. 